\title{
Late marriage and the HIV epidemic in sub-Saharan Africa
}

John Bongaarts

Population Council

Follow this and additional works at: https://knowledgecommons.popcouncil.org/departments_sbsr-pgy

Part of the Demography, Population, and Ecology Commons, and the International Public Health Commons

How does access to this work benefit you? Let us know!

\section{Recommended Citation}

Bongaarts, John. 2006. "Late marriage and the HIV epidemic in sub-Saharan Africa," Policy Research Division Working Paper no. 216. New York: Population Council. Version of record: https://doi.org/ $10.1080 / 00324720601048343$ 


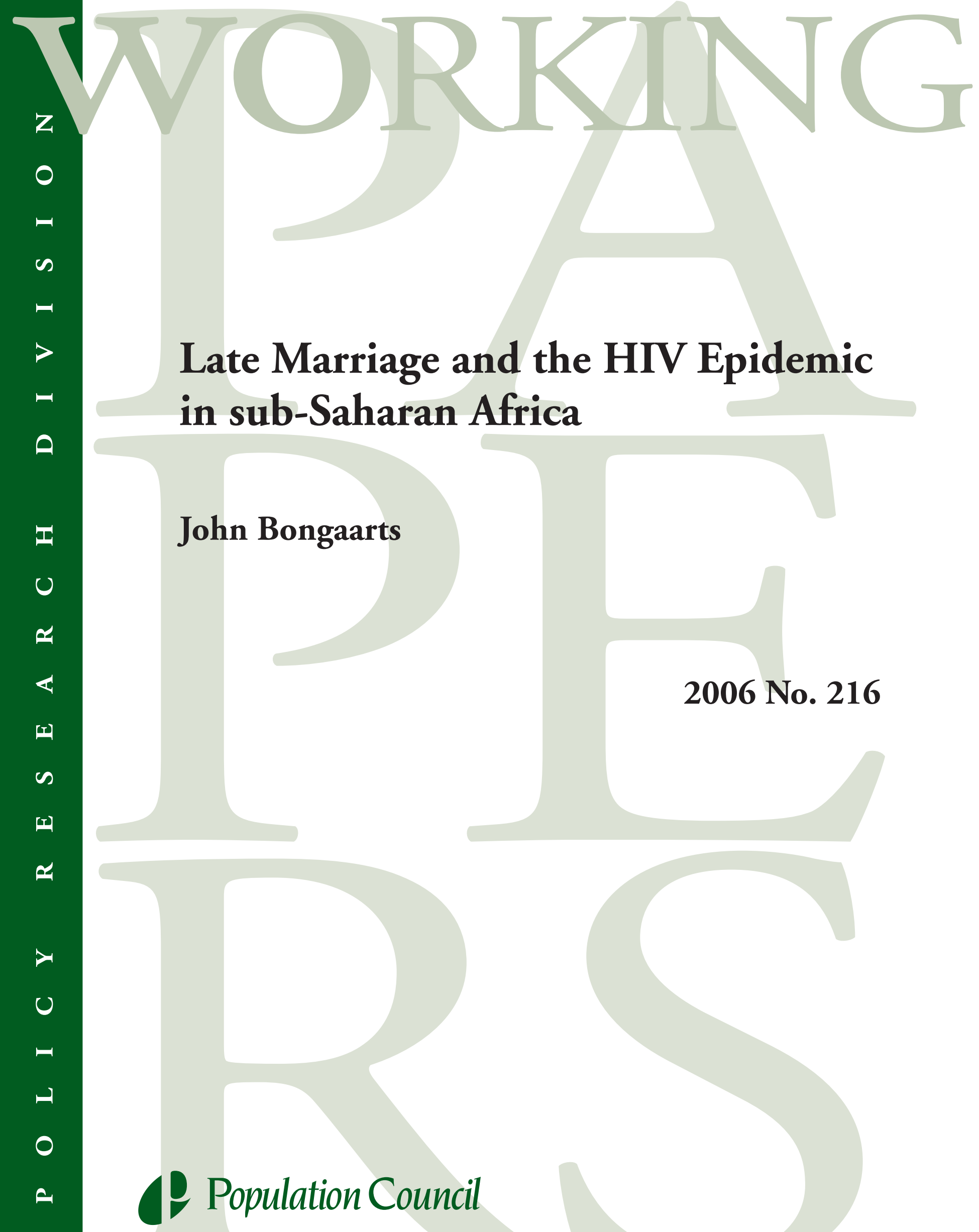




\section{(1) Population Council}

One Dag Hammarskjold Plaza

New York, New York 10017 USA

www.popcouncil.org

pubinfo@popcouncil.org

This material may not be reproduced without written permission from the author. For a list of Policy Research Division Working Papers, including those that are currently available for downloading in PDF format, see www.popcouncil.org/publications/wp/prd/rdwplist.html.

ISSN: $1554-8538$

(C) 2006 The Population Council, Inc. 


\title{
Late Marriage and the HIV Epidemic in sub-Saharan Africa
}

\author{
John Bongaarts
}

John Bongaarts is Vice President, Policy Research Division, Population Council, New York.

Acknowledgments: This research was funded in part through grants from the William and Flora Hewlett Foundation and the Andrew W. Mellon Foundation. The author thanks Paul Hewett and Monica Grant for assistance in the analysis of DHS data. 


\begin{abstract}
The causes of wide variation in the sizes of HIV epidemics among countries in subSaharan Africa are not well understood. This study assesses the potential roles of late age at marriage and a long period of premarital sexual activity as population risk factors for HIV infection in the region. The relationship between marital status and the prevalence and incidence of HIV is examined with ecological data from 33 sub-Saharan African countries and with individual-level data from nationally representative Demographic and Health Surveys in Kenya and Ghana in 2003. The ecological analysis finds a significant positive correlation between HIV prevalence and the median age at first marriage, and between HIV prevalence and the interval between first sex and first marriage. In the individual-level analysis, the risk for HIV infection per year of exposure among sexually active women is higher before than after first marriage. These findings support the hypothesis that a high average age at marriage in a population leads to a long period of premarital sex during which partner changes are relatively common, thus facilitating the spread of HIV.
\end{abstract}


Since the identification of the human immunodeficiency virus in the early 1980 s, much has been learned about how the virus is transmitted and how it attacks the body's immune system and causes AIDS. This knowledge has provided the basis for the development of increasingly effective antiretroviral therapies, and researchers continue the quest to develop microbicides and vaccines. Considerably less progress has been made in understanding the epidemiology of HIV. In particular, the social and behavioral determinants and the geographic distribution of AIDS are not well understood.

One of the most puzzling features of the HIV epidemic in sub-Saharan Africa is the large variation in its size among countries. The proportion of adults infected ranges from 33 percent in Swaziland to less than 1 percent in Mauritania, Madagascar, and Senegal (UNAIDS 2006). Several factors are believed to be conducive to large epidemics: high frequency of sexual intercourse outside marriage, multiple sexual partners, lack of condom use, lack of male circumcision, and infection with other sexually transmitted diseases (Cameron et al. 1989; Quinn et al. 2000; Caldwell 2000; Shapiro 2002). The evidence for an important effect of genital ulcer disease and male circumcision practices is strong (Cameron et al. 1989; Halperin and Bailey 1999; Weiss et al. 2000; Buvé et al. 2001; Auvert et al. 2001; Bailey et al. 2001). In contrast, it has proven difficult to demonstrate that variation in sexual behavior has a prominent role in the epidemic, even though heterosexual intercourse is the main mode of HIV transmission in sub-Saharan Africa. As noted by Cleland et al. (2004a, p. iil): "Thus far behavioral data have had relatively weak explanatory power for elucidation of cross national differences."

The present study examines the hypothesis that late average age at marriage is another factor contributing to the spread of HIV because late marriage may lead to a long period of premarital sexual activity. Throughout the developing world marriage is the central social institution that regulates and sanctions sexual behavior. This suggests that age at marriage and sexual behavior before and after marriage could play a role in the spread of HIV, but despite a few notable efforts (Orubuloye et al. 1994; Caraël 1995; Cleland and Ferry 1995; Bracher et al. 2003; Cleland et al. 2004b; Clark 2004; Spark-du Preez et al. 2004), these factors have been neglected in past research. One reason for this neglect is that the role of the timing of marriage in the epidemic is not obvious and the evidence on this issue appears to be conflicting. Ecological data indicate that countries in southern Africa with very late age at marriage also have large epidemics. However, some recent studies suggest that young married women are at higher risk of infection than unmarried sexually active women (Auvert et al. 2001; Clark 2004). These issues will be examined below, using both ecological data for sub-Saharan African countries and individual-level data from Kenya and Ghana.

\section{DATA AND METHODS}

The ecological analysis relies on country-level epidemiological and demographic data from 33 countries in sub-Saharan Africa. Estimates of HIV prevalence among women aged 15-49 in 2005 are taken from UNAIDS (2006). Estimates of median ages at 
first marriage and at first sex are calculated from nationally representative Demographic and Health Surveys (DHS). In a typical DHS survey several thousand women of reproductive age (15-49) are interviewed and information is collected on a wide array of demographic, behavioral, and health topics. Median ages at events for women are calculated from current status information in all countries for which the individual data files were available for analysis. ${ }^{1}$ The reported proportions having ever experienced the event at the time of the survey by single age are calculated and then smoothed using a three-year moving average. The median is the age at which this proportion reaches 50 percent. Following DHS convention, the term "marriage" refers to both formal marriages and consensual unions.

In countries with multiple DHS surveys only data from the latest available year is used. As a result, the year in which the median age at first sex and first marriage are estimated from the DHS ranges from 1986 to 2004. This is earlier than the year of the HIV estimate: 2005. This difference is unlikely to be a significant problem for two reasons. First, the timing of first sex has, on average, changed little over time. In the 17 sub-Saharan African countries with at least two DHS surveys, the trend in the median age at first sex showed a negligible average decline of -0.001 years per year between the two most recent surveys. The corresponding trend in the median age at first marriage was slightly positive with an average increase of 0.057 years per year. Second, the time of infection with HIV is generally several years before the year in which HIV prevalence is measured, because, on average, individuals live for about a decade between the time of infection and death from AIDS.

Individual-level analysis in the present study relies on DHS surveys conducted in Kenya and Ghana in 2003 (Central Bureau of Statistics, Kenya et al. 2004; Ghana Statistical Service et al. 2004). These surveys are among the first to measure HIV status in a nationally representative sample of women and men. In most other countries in subSaharan Africa national HIV prevalence estimates are derived from sentinel surveillance of pregnant women attending antenatal clinics, which may result in bias for a number of reasons (Zaba et al. 2000; Zaba et al. 2005b). Survey estimates may also contain some bias because a small proportion of respondents decline to be tested. In the Kenya DHS 14.4 percent of 4,303 eligible women refused to be tested for HIV, and in the Ghana DHS 5.7 percent of the 5,940 eligible women refused. However, comparisons of women who did and did not consent indicate little or no evidence for a consistent relationship between consent status and variables associated with higher HIV risk (Central Bureau of Statistics, Kenya et al. 2004; Ghana Statistical Service et al. 2004). Survey estimates of prevalence are therefore widely accepted as reasonable and preferable to estimates derived from antenatal clinic data (UNAIDS 2006). In addition, the ability to link HIV status to other information collected in standard DHS surveys provides a unique opportunity to examine the socioeconomic, demographic, and behavioral correlates of HIV infection (Zaba et al. 2005a). Logistic regression analysis is used to estimate the effects of marital status on the risk of infection. 


\section{Results of ECOLOGiCAl ANALYSIS}

The median ages at first sex for women in the 33 countries in sub-Saharan Africa fall within a relatively narrow range between 16.3 and 20.8 years. Some underreporting of sex and overreporting of age at first sex among never-married women is likely, and these medians therefore are probably slight overestimates, in particular in countries with the highest reported medians (Caraël 1995; Zaba et al. 2004). As shown in Figure 1, the median age at first marriage has a much wider range-from 16.3 years in Niger to 28.9 years in Namibia. The four highest median ages at first marriage are found in Botswana (25.7), Swaziland (25.8), South Africa (26.7) and Namibia (28.9). These four countries have some of the largest HIV epidemics in the world.

Simple correlation analyses were undertaken as a first step in the assessment of a potential role of the timing of first sex and first marriage. Figure 2 plots HIV prevalence in the 33 countries by the median age at first sex. The correlation between these two variables is not statistically significant. In contrast, as shown in Figure 3, the correlation between HIV prevalence and the median age at first marriage for these countries is positive and highly significant $(\mathrm{r}=0.61, \mathrm{p}<0.001)$. These findings suggest that epidemic size is related to the interval between age at first sex and age at first marriage. Figure 4 plots HIV prevalence by the difference between median ages at first marriage and first sex. The correlation is again positive and highly significant $(\mathrm{r}=0.63, \mathrm{p}<0.001)$.

The association evident in Figure 4 may be due in part to the confounding effect of other risk factors. One of the best established of these factors is male circumcision. The correlation between HIV prevalence and the proportion of males circumcised is 0.63 $(p<0.001)$ for the 33 countries. To determine the separate roles of delayed marriage and male circumcision, a multivariate regression is calculated in which HIV prevalence is the dependent variable and the proportion of males circumcised and the difference between the median ages at first sex and first marriage are the explanatory variables. The results from this regression are summarized in Table 1. Both explanatory variables have highly significant effects on HIV prevalence in the expected direction: an additional year of premarital sex raises HIV prevalence by 1.52 percent $(\mathrm{p}<0.001)$ and a 10 percent increase in circumcision reduces prevalence by 1.28 percent $(\mathrm{p}<0.001)$. These two risk factors together explain 64 percent of the between-country variation in HIV prevalence.

The results in Figures 3 and 4 indicate that countries with late marriage and high HIV prevalence are concentrated in southern Africa (the exception is Lesotho, which is surrounded by South Africa and has high prevalence but not late marriage). To examine regional differences within sub-Saharan Africa, Table 2 presents unweighted averages of various indicators for three regional groupings of the 33 countries: West $(\mathrm{N}=12)$, East/Middle $(\mathrm{N}=16)$, and South $(\mathrm{N}=5)$. HIV prevalence is lowest in the West $(2.5$ percent), intermediate in the East/Middle (7.9 percent), and highest in the South (23.8 percent), and the differences between regions are all statistically significant. As expected from the regression results, the South also has a significantly higher median age at first marriage (25.4 years) than the East/Middle (19.2 years) and West (19.1 years). In addition, the South has a significantly lower male circumcision rate (21.2 percent) than 
the other regions. There are no significant differences between East/Middle and West in the median age at first sex or in the median age at first marriage. However, the East/Middle has a significantly lower male circumcision rate than the West (46.9 percent vs. 77.8 percent) and this may in part explain the higher HIV prevalence in the East/Middle.

The preceding ecological analysis focused on intercountry and interregional differences in the timing of marriage and in HIV prevalence. Another ecological dimension can shed light on this relationship: urban vs. rural areas within countries. Although reliable estimates of urban and rural HIV prevalence are lacking, it is well established that urban prevalence is significantly higher in many countries (UNAIDS 2006). The question then is whether the association between late age at marriage and the size of the HIV epidemic also exists for urban-rural differences. Figure 5 presents averages of the median ages at first sex and first marriage in urban and rural areas for 32 countries (estimates are not available for Swaziland). The results show that the median age at first marriage in urban areas (20.4 years) exceeds that of rural areas (18.5 years) by 1.9 years, on average. An urban-rural difference in median age at first sex also exists (17.9 vs. 17.0), but it is smaller than for age at marriage. As a result, the interval of premarital sex is significantly larger in urban than in rural areas (1.9 vs. 0.9 years, $\mathrm{p}<0.01)$.

All of these ecological results are consistent with the hypothesis that a long interval of premarital sex contributes to the spread of HIV. Ecological evidence should be used with caution because it does not prove a causal relationship, and the observed associations could be in part due to unobserved country-specific factors. The following analysis investigates this issue with individual-level data.

\section{RESULTS OF INDIVIDUAL-LEVEL ANALYSIS IN KENYA AND GHANA}

The discussion of results focuses on Kenya, but comparable statistics for Ghana are included in the tables and figures. Estimates for Kenya are more robust than for Ghana because Kenya's HIV prevalence is more than twice the level in Ghana.

The median age at first sex for Kenyan women in 2003 is 18.1 years, and by the mid-20s nearly all women report having ever had sex. The median age at first marriage is 20.5 years, and after age 30 all but a few percent of women have ever married. These medians have changed little in the decade between the 1993 and 2003 DHS surveys. The proportion previously married is very small before age 20 and rises slowly with age. In Ghana the median ages at first sex and first marriage are 18.2 and 20.1 respectively, indicating a slightly shorter interval of premarital sex than in Kenya.

\section{Current HIV status}

Some 8.7 percent of women aged 15-49 in the DHS sample tested positive for HIV. HIV prevalence is higher for currently married than for never-married women (8.0 vs. 4.7 percent). The formerly married have still higher levels of infection (23.7 percent). One reason for the low prevalence among never-married women is that a proportion of 
them have never been sexually active. HIV prevalence among the never married who have had sex (8.7 percent) is slightly higher than among the currently married (8.1) and slightly lower than among the ever married (10.7 percent). These estimates are difficult to interpret because they are not adjusted for differences in age distributions.

HIV prevalence by age and by marital/cohabitation status among women in Kenya and Ghana who have ever had sex is presented in Table 3. HIV prevalence in Kenya shows a typical inverted U-shape pattern by age, reaching a maximum at 13.3 percent in age group 25-29. HIV prevalence varies considerably by cohabitation status, from a low of 7.6 percent among formally married women to a high of 30.2 percent among widows. Compared to the reference group of the formally married, the adjusted odds ratios for all other cohabitation groups are higher than one, but these effects are only significant for the widows and separated groups. The last column of Table 3 presents odds ratios for cohabitation status that have been adjusted for age and years since first sex. The results are very similar to those for odds ratios that are adjusted for age only.

These results regarding the relationship between current marital/cohabitation status and current HIV status should be interpreted with caution. The problem is that marital status at the time of infection is not known. Women who test positive at the time of the survey were infected at some earlier time, which may be as long as a decade ago. This implies that a substantial proportion of women in one status (e.g., currently married) might have been infected while they were in another status (e.g., never married). To explain present HIV status it is necessary to look at past behavior.

\section{Past exposure to risk of infection}

The large majority of HIV infections in sub-Saharan Africa are the result of heterosexual transmission. One would therefore expect the probability that a women is infected at given age to be positively related to the number of years she has been sexually active. This issue will now be explored with a multivariate regression analysis of the HIV status of women aged 15-29. Years since first sex is the main explanatory variable of interest, and controls are included for the confounding effects of age, ever-married status, years of education, and urban or rural residence. The results from this regression are summarized in Table 4, model 1. The odds ratio for each year since first sex is significantly higher than 1 , which implies that prevalence rises with duration of exposure. The effects of marital status (ever married), rural/urban residence, years of education, and age are not significant.

Because DHS surveys do not provide information about marital status at the time of infection, there is no direct way to determine whether exposure before or after marriage is riskier. But it is possible to shed light on this issue by dividing the interval of exposure since first sex into two components: years of exposure before marriage (i.e., between first sex and first marriage) and after first marriage (i.e., between age at first marriage and the respondent's current age). This approach is used in a second regression, which includes these two new explanatory variables instead of years since first sex (marital status is dropped owing to co-linearity). The results (Table 4, model 2) show that 
the odds ratios for each additional year of exposure before and after marriage are both significantly higher than 1.0. (Repeating the regressions including only currently or evermarried women gave very similar results.) This indicates that increased duration of exposure raises HIV prevalence regardless of whether the exposure occurs before or after marriage. The annual risk of infection is significantly higher for exposure before than after marriage (odds ratios of 1.21 vs. 1.11 in Kenya and 1.22 vs. 1.08 in Ghana). This finding is consistent with a recent study by Zaba et al., which used a similar multivariate analysis with data from an antenatal clinic (ANC) surveillance study in Tanzania $(7,000$ women) and found that each year of exposure to premarital sex was associated with an odds ratio of 1.12 and each year of marital exposure gave an odds ratio of 1.08 (Zaba et al. 2005a). These estimates are summarized in Figure 6, which plots odds ratios for HIV infection by marital status for Kenya and Ghana and compares them with the estimates from the Tanzanian ANC study.

The main finding from these regressions is that the odds ratios for HIV infection before first marriage exceed those after marriage in all three populations. This difference reflects a higher incidence rate of HIV infection among women before marriage compared with after marriage. In reaching this interpretation, one should keep in mind that the estimates in Table 4 are derived from information on women who survived to be interviewed in the DHS survey. These odds ratios are downwardly biased estimates of the true odds ratios at the time of infection because mortality between the time of infection and the time of the survey is higher for infected than for uninfected individuals. Odds ratio differences by marital status are affected by this bias because the average age at infection before marriage is somewhat lower than the average age at infection among the ever married. As a result, the downward bias is larger among the never married than among the ever married. This bias makes it more difficult to establish the effects of marital status, and the actual differences between odds ratios before and after first marriage are therefore probably larger than the differences estimated from the regressions in Table 4.

The marital status differentials in odds ratios for HIV infection in Kenya and Ghana and in the Tanzanian ANC study are consistent with HIV incidence differentials observed in a unique prospective study in the Rakai district of Uganda. Direct estimates of HIV incidence by marital status are available from annual surveillance between 1994 and 2004 of a population of approximately 12,000 adults aged 15-49 in 50 rural communities in Rakai. Gray et al. report a current incidence of 1.9 percent per year for sexually active never-married women and 1.2 percent per year for currently married women (Gray et al. 2004). Figure 6 (right axis) plots these estimates of current HIV incidence rates for never-married and currently married women in Rakai and compares them with the odds ratios for Ghana, Kenya, and the Tanzania ANC study. In these four populations the risk of HIV infection per year of exposure among currently or evermarried women is substantially lower than among sexually active never-married women. 


\section{DISCUSSION}

Two risk factors likely explain the higher risk of HIV infection among sexually active never-married women: a higher rate of partner change and higher infectivity of partners.

Epidemic models have demonstrated the critical role of a high rate of new partner acquisition in the spread of epidemics (Anderson 1999). For uninfected individuals, frequent partner change raises the risk of encountering an infected partner, and for infected individuals any new partner implies a new chance to spread the infection. Concurrent partnerships appear to be particularly conducive to the spread of HIV through networks of individuals (Morris and Kretzschmar 1997; Halperin and Epstein 2004). According to the DHS in Kenya, the average number of partners in the past year was lower for never-married than for currently married women (0.59 vs. 0.98 partners/year), but for nearly all married women the partner is the husband. Among currently married women the proportion who had a non-spousal partner in the past year is only 2 percent, which is much lower than among never-married women who have ever had sex (57 percent). The difference between married and never-married women is probably smaller than these estimates suggest, because underreporting of nonmarital partners tends to be higher among married than among single women (Nnko et al. 2004)

The infectivity of partners is not measured in the DHS, but a brief discussion of this issue is desirable. The level of infectivity (i.e., the rate of transmission from an infected to an uninfected individual per sexual contact) depends strongly on time since infection. Infectiousness is very high for a few months after the acquisition of HIV (Anderson 1996, 1999; Koopman et al. 1997; Shiboski and Padian 1998; Pilcher et al. 2004; Wawer et al. 2005). Following this initial episode of high infectivity, the rate of transmission declines to very low levels for most HIV-positive individuals for a period of years during which HIV infection is latent and disease is not evident. This pattern is clearly documented in Rakai, where the average rate of transmission between an infected and uninfected individual is estimated at 0.0012 per sexual act in HIV-discordant couples, but this rate was an order of magnitude higher in the first 2.5 months after infection ( 0.008 per coital act) than in the latent period before the onset of AIDS and death ( 0.0007 per act) (Wawer et al. 2005). Infectiousness rises again years after infection as the onset of AIDS approaches, but reduced frequency of intercourse due to illness and changes in the virus within the host limit the epidemiological implications of this increase (Anderson 1996, Wawer et al. 2005). Infected individuals are therefore most infectious during the first few months following infection.

This pattern of sharply declining infectiousness over time among infected individuals has several significant implications for the evolution of the epidemic. First, model simulations demonstrate that this pattern dominates the transmission dynamics both early and late in the course of epidemics (Koopman et al. 1997). Second, it probably partly explains the paradoxical finding by Kelly et al. that the incidence of HIV declines as husbands become older (Kelly et al. 2003). Older husbands tend to have higher HIV prevalence levels than their younger counterparts, but they are also less infectious 
because they have been infected for a longer period. Third, and most important for present purposes, the pattern of declining infectivity provides a potential partial explanation for the higher odds ratios for HIV infection among never-married than among ever-married women as discussed above. The partners of currently married women are on average older than the partners of unmarried women. For example, in Rakai the proportion of male sexual partners of 15-19-year-old women who were less than five years older was 75 percent among single women and only 40 percent among married women (Kelly et al. 2003). The duration since infection is longer for older than for younger infected men, and this longer duration is associated with reduced infectivity.

These two risk factors elevate the risk of infection among unmarried women compared to married women. Other risk factors have the reverse effect. In particular, married women typically have higher frequency of intercourse and lower condom use than their unmarried counterparts (Clark 2004). As noted, the HIV status of a sexual partner is another relevant risk factor. The DHS provides the HIV status of male partners among couples (but not for unmarried women). For uninfected married women aged 1519, no male partner was found to be HIV positive in either Kenya or Ghana (Central Bureau of Statistics, Kenya et al. 2004; Ghana Statistical Service et al. 2004). Sample sizes are too small to draw firm conclusions from this finding, however.

In general, one set of risk factors puts unmarried women at elevated risk (e.g., frequent partner change, higher infectiousness of partners), while another set can raise the risk for married women (e.g., higher frequency of intercourse, lack of condom use, higher infection level of partner). These two sets of factors are partially offsetting. The above findings on differences in odds ratios for HIV infection by marital status suggest that the effects of the second set do not fully offset the effects of the first set, thus leaving unmarried sexually active women with a net elevated risk of infection.

The number of infections in a population is determined by the number of women at risk in each marital status category as well as by the incidence of infection per year in each status. Over the life cycle women spend, on average, more years in marriage than they spend being sexually active before marriage, and the annual risk of infection within marriage is substantial, even though it is lower than before marriage. As a result, more infections occur within than before marriage, despite differentials in incidence. Nevertheless, the higher the proportion of sexually active years women spend before rather than after first marriage, the higher the average risk of infection in the population. Other things being equal, a later age at marriage raises the proportion of women in the premarital status with relatively high infection risk, thus facilitating the more rapid spread of infection.

Clark (2004) argues that early marriage puts adolescents at risk of HIV infection and that efforts should be made to assist this vulnerable group to protect themselves. This argument is persuasive and can readily be reconciled with the findings of the present study. The key issue is the timing of first marriage in relation to the timing of first sex. If a young girl marries before the age at which she would otherwise become sexually active (around age 18 in much of sub-Saharan Africa), then she is exposed to an elevated risk of infection that would not occur in the absence of early marriage. This is particularly the 
case because young wives are usually expected to bear a child soon after marriage and have little bargaining power to insist on condom use if they suspect that their husbands are unfaithful. However, if marriage is delayed significantly beyond the average age at first intercourse, then the prevalence and duration of premarital sex rise, putting women and men at elevated risk for the reasons given above.

\section{CONCLUSION}

The ecological evidence reviewed here indicates that sub-Saharan African countries with high age at marriage and long intervals of premarital sex tend to have large HIV epidemics. Low rates of male circumcision are also conducive to the spread of the epidemic. Together these two risk factors explain 64 percent of the variation in HIV prevalence in 33 sub-Saharan countries.

The individual-level analysis of DHS data in Kenya and Ghana finds that being married is less risky per year of exposure than being sexually active and never married. The elevated risk of infection among never-married sexually active women is likely caused by a higher rate of partner change and higher levels of infectivity among partners of never-married than of married women. These findings support the hypothesis that a high average age at marriage in a population contributes to the spread of HIV because a higher age at marriage is associated with a longer period of premarital exposure to the risk of infection. Very early marriage also raises the risk of infection for young girls, because they would otherwise not be at risk, but marriage after the age at first intercourse raises exposure to risky premarital sex. This last appears to be a key factor in countries with the largest epidemics. For example, in several southern African countries the average interval between age at first sex and first marriage is about a decade. During this decade frequent partner change and high partner infectiousness contribute to the rapid spread of HIV. 


\section{NoTe}

1 Estimates of current median ages at first sex and first marriage are calculated from the individual data files for 28 countries. In four other countries the medians for women aged 25-29 published in the first country report are used because data files were not available. For Swaziland no DHS was available and the median age at first marriage is calculated from proportions ever married by age from United Nations (2000), and the median age at first sex was set equal to the average of the medians in the four other countries in southern Africa. 
Table 1 Regression estimates (OLS) of effects of years of premarital sex and male circumcision on HIV prevalence (percent) in 33 sub-Saharan countries

\begin{tabular}{lcc} 
& Coefficient & $\mathrm{p}$ value \\
\hline Difference between median ages at first sex and first marriage (yrs) & 1.52 & $<0.001$ \\
Percentage of males circumcised & -0.128 & $<0.001$ \\
Constant & 11.4 & $<0.001$ \\
$\mathrm{~N}$ & 33 & \\
$\mathrm{R}^{2}$ & 0.64 & \\
\hline
\end{tabular}

Source: DHS data files; UNAIDS 2006; Wendell and Werker 2004

Table 2 HIV prevalence, median ages at first sex and first marriage, and proportion of males circumcised, unweighted country averages by region

\begin{tabular}{lrccr}
\hline & \multicolumn{3}{c}{ Region } & \\
\cline { 2 - 4 } & West & East/Middle & South & \multicolumn{1}{c}{ Total } \\
\hline HIV prevalence (\%) & 2.5 & $7.9^{*}$ & $23.8^{*}$ & 9.7 \\
Median age at first sex (yrs) & 17.2 & 17.7 & 17.7 & 17.5 \\
Median age at first marriage (yrs) & 19.1 & 19.2 & $25.4^{*}$ & 20.1 \\
Difference between first sex and & 1.9 & 1.4 & $7.7^{*}$ & 2.6 \\
$\quad$ first marriage (yrs) & 77.8 & $46.9^{*}$ & $21.2^{*}$ & 54.3 \\
Circumcised males (\%) & 12 & 16 & 5 & 33 \\
N & & & &
\end{tabular}

* Significantly different from West Africa $(\mathrm{p}<0.05)$

Source: DHS data files; UNAIDS 2006; Wendell and Werker 2004 
Table 3 HIV prevalence and adjusted odds ratio by age group and cohabitation status among women who have ever had sex

\begin{tabular}{|c|c|c|c|c|}
\hline \multicolumn{5}{|l|}{ KENYA } \\
\hline \multirow[b]{2}{*}{ Age group } & \multirow[b]{2}{*}{ Prevalence $(\%)$} & \multirow[b]{2}{*}{$\mathrm{N}$} & \multicolumn{2}{|c|}{ Odds ratio $(95 \% \mathrm{CI})$} \\
\hline & & & Adjusted for age & $\begin{array}{l}\text { Adjusted for age and } \\
\text { years since first sex }\end{array}$ \\
\hline $15-19$ & 4.6 & 309 & & \\
\hline $20-24$ & 10.3 & 565 & & \\
\hline $25-29$ & 13.3 & 507 & & \\
\hline $30-34$ & 11.8 & 435 & & \\
\hline $35-39$ & 11.8 & 345 & & \\
\hline $40-44$ & 9.5 & 275 & & \\
\hline $45-49$ & 3.9 & 201 & & \\
\hline \multicolumn{5}{|l|}{ Cohabitation status } \\
\hline Never married & 8.7 & 403 & $1.49(0.87-2.55)$ & $1.55(0.87-2.8)$ \\
\hline Married (formal) & 7.6 & 1721 & 1 & 1 \\
\hline Living together & 11.3 & 176 & $1.52(0.86-2.68)$ & $1.45(0.82-2.57)$ \\
\hline Widowed & 30.2 & 133 & $7.96(4.76-13.29)$ & $8.14(4.7-14.1)$ \\
\hline Divorced & 16.5 & 41 & $2.37(0.90-6.26)$ & $2.62(0.99-6.92)$ \\
\hline Separated & 19.9 & 162 & $2.99(1.83-4.87)$ & $3.17(1.91-5.27)$ \\
\hline Total & 10.1 & 2636 & & \\
\hline \multicolumn{5}{|l|}{ GHANA } \\
\hline \multirow[b]{2}{*}{ Age group } & \multirow[b]{2}{*}{ Prevalence $(\%)$} & \multirow[b]{2}{*}{$\mathrm{N}$} & \multicolumn{2}{|c|}{ Odds ratio $(95 \% \mathrm{CI})$} \\
\hline & & & Adjusted for age & $\begin{array}{l}\text { Adjusted for age and } \\
\text { years since first sex }\end{array}$ \\
\hline $15-19$ & 1.3 & 411 & & \\
\hline $20-24$ & 2.3 & 766 & & \\
\hline $25-29$ & 3.5 & 838 & & \\
\hline $30-34$ & 4.2 & 703 & & \\
\hline $35-39$ & 4.7 & 647 & & \\
\hline $40-44$ & 3.0 & 504 & & \\
\hline $45-49$ & 2.5 & 437 & & \\
\hline \multicolumn{5}{|l|}{ Cohabitation status } \\
\hline Never married & 2.5 & 651 & $1.58(0.73-3.39)$ & $1.54(0.69-3.42)$ \\
\hline Married (formal) & 2.7 & 2772 & 1 & 1 \\
\hline Living together & 4.5 & 420 & $1.98(1.13-3.49)$ & $2.07(1.17-3.67)$ \\
\hline Widowed & 6.7 & 95 & $3.05(1.29-7.20)$ & $3.01(1.20-7.56)$ \\
\hline Divorced & 4.5 & 167 & $1.65(0.68-3.97)$ & $1.75(0.73-4.22)$ \\
\hline Separated & 7.6 & 201 & $3.26(1.69-6.27$ & $2.69(1.29-5.63)$ \\
\hline Total & 3.2 & 4306 & & \\
\hline
\end{tabular}

Source: DHS data files. 
Table 4 Odds ratios for effects of duration of exposure to infection on HIV status among sexually active women aged 15-29

\begin{tabular}{|c|c|c|c|}
\hline & & \multicolumn{2}{|c|}{ Odds ratio $(95 \% \mathrm{CI})$} \\
\hline & & Model 1 & Model 2 \\
\hline \multirow[t]{9}{*}{ KENYA } & Years since first sex & $1.16(1.07-1.26)$ & \\
\hline & $\begin{array}{c}\text { Exposure before first } \\
\text { marriage (yrs) }\end{array}$ & & $1.21(1.12-1.31)$ \\
\hline & $\begin{array}{l}\text { Exposure after first } \\
\text { marriage (yrs) }\end{array}$ & & $1.11(1.02-1.21)$ \\
\hline & Urban residence & $1.45(0.92-2.29)$ & $1.37(0.86-2.18)$ \\
\hline & Years of education & $1.05(0.99-1.12)$ & $1.02(0.96-1.09)$ \\
\hline & Age & $2.22(0.98-4.99)$ & $2.36(1.08-5.19)$ \\
\hline & Age squared & $0.98(0.97-1.00)$ & $0.98(0.97-1.00)$ \\
\hline & Ever married & $1.44(0.78-2.65)$ & \\
\hline & $\mathrm{N}$ & 1364 & 1364 \\
\hline \multirow[t]{9}{*}{ GHANA } & Years since first sex & $1.15(1.00-1.32)$ & \\
\hline & $\begin{array}{c}\text { Exposure before first } \\
\text { marriage (yrs) }\end{array}$ & & $1.22(1.07-1.40)$ \\
\hline & $\begin{array}{l}\text { Exposure after first } \\
\text { marriage (yrs) }\end{array}$ & & $1.08(0.94-1.24)$ \\
\hline & Urban residence & $1.14(0.54-2.39)$ & $1.02(0.48-2.17)$ \\
\hline & Years of education & $1.00(0.92-1.08)$ & $0.98(0.91-1.05)$ \\
\hline & Age & $0.63(0.20-1.98)$ & $0.54(0.19-1.58)$ \\
\hline & Age squared & $1.01(0.99-1.03)$ & $1.01(0.99-1.04)$ \\
\hline & Ever married & $0.89(0.32-2.50)$ & \\
\hline & $\mathrm{N}$ & 2009 & 2009 \\
\hline
\end{tabular}

Source: DHS data files. 
Figure 1 Distribution of median age at first marriage for 33 countries in sub-Saharan Africa

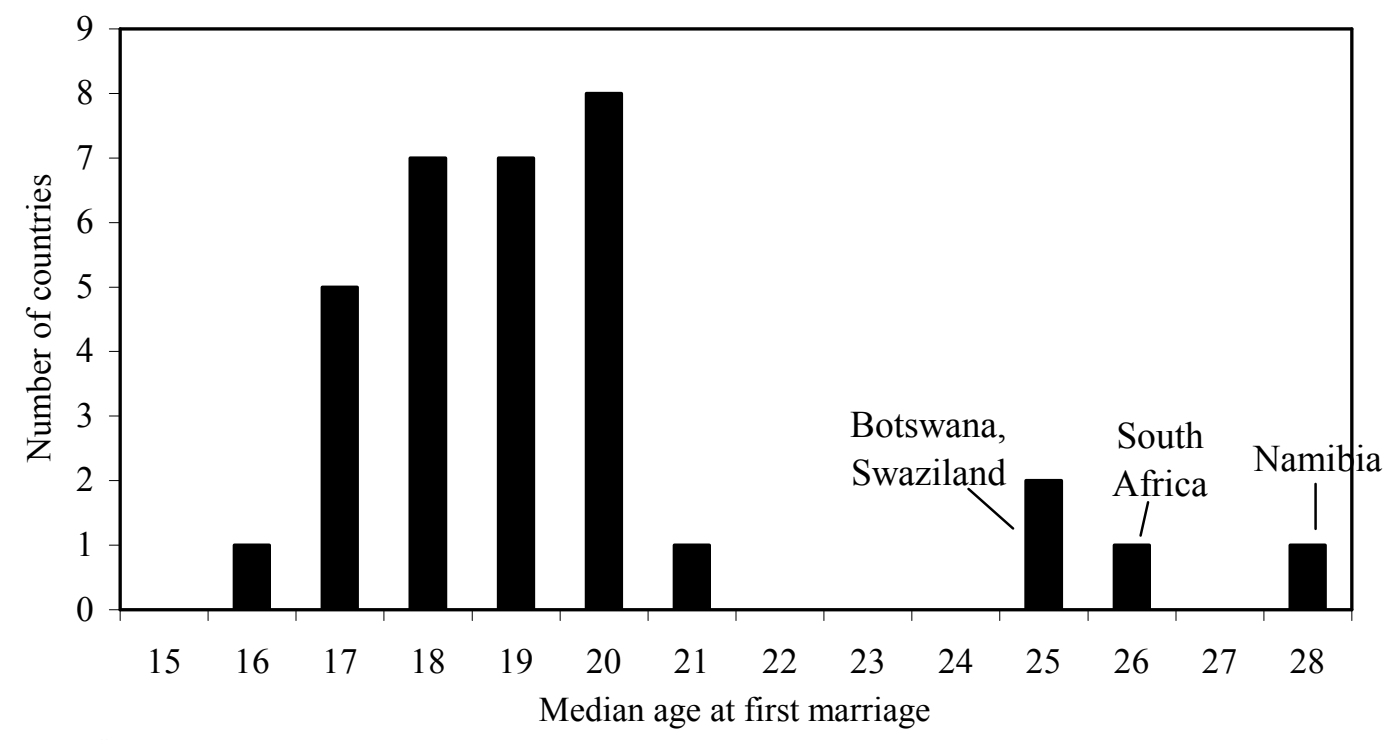

Source: DHS

Figure 2 Relationship between HIV prevalence and median age at first sex for women, 33 countries in sub-Saharan Africa

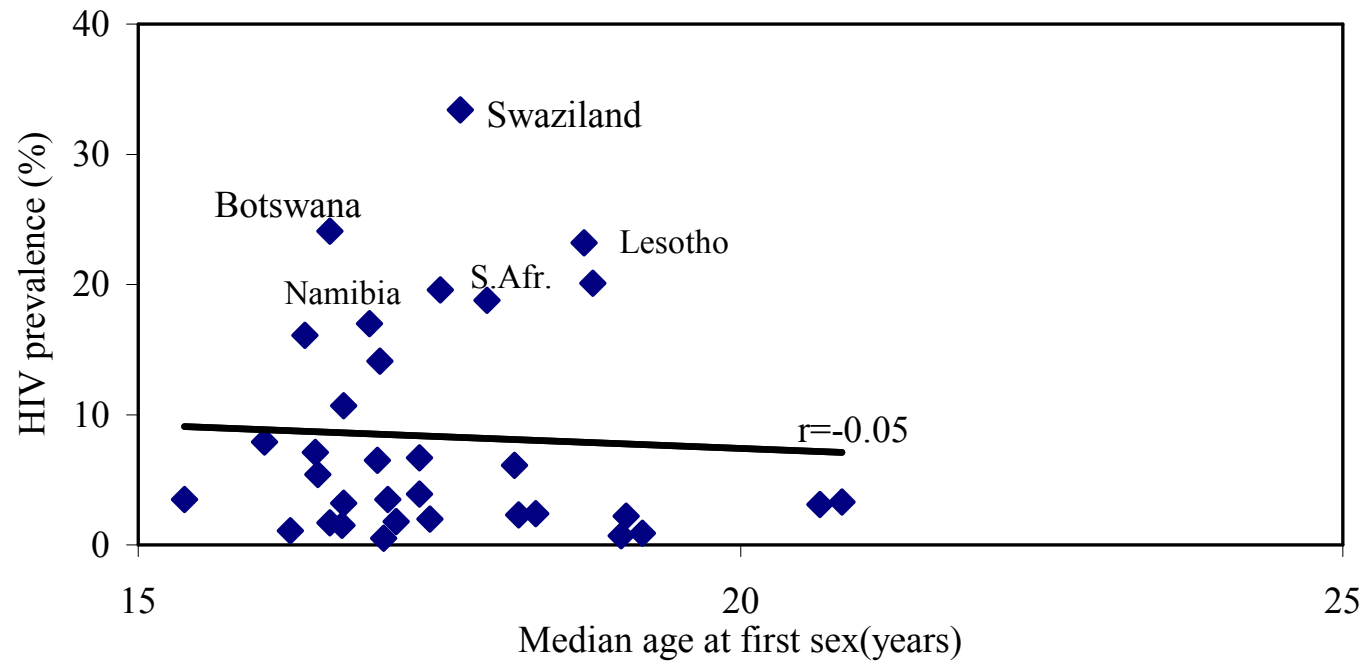

Source: DHS; UNAIDS 2006 
Figure 3 Relationship between HIV prevalence and median age at first marriage for women, 33 countries in sub-Saharan Africa

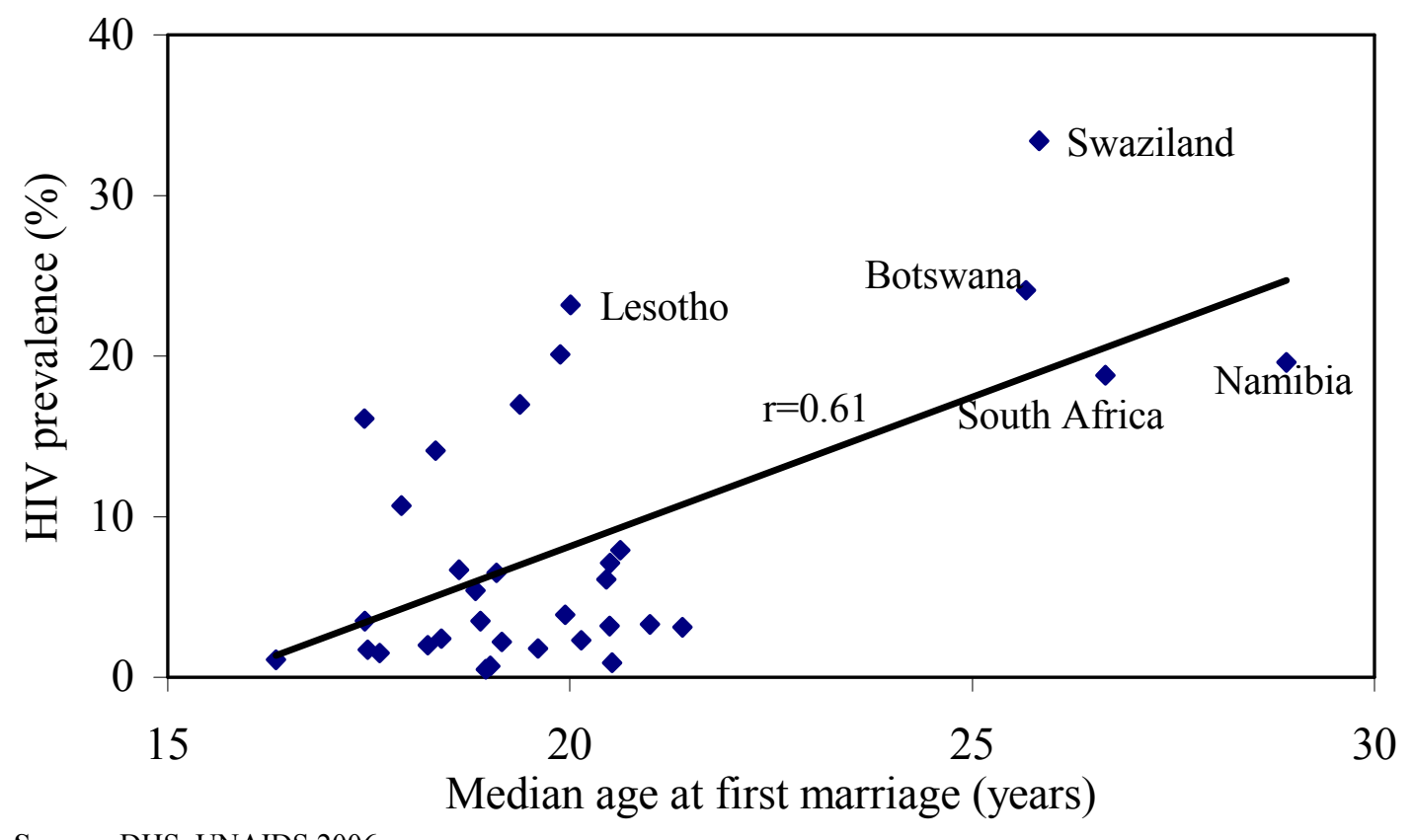

Source: DHS; UNAIDS 2006

Figure 4 Relationship between HIV prevalence and the difference between median age at marriage and median age at first sex, 33 countries in sub-Saharan Africa

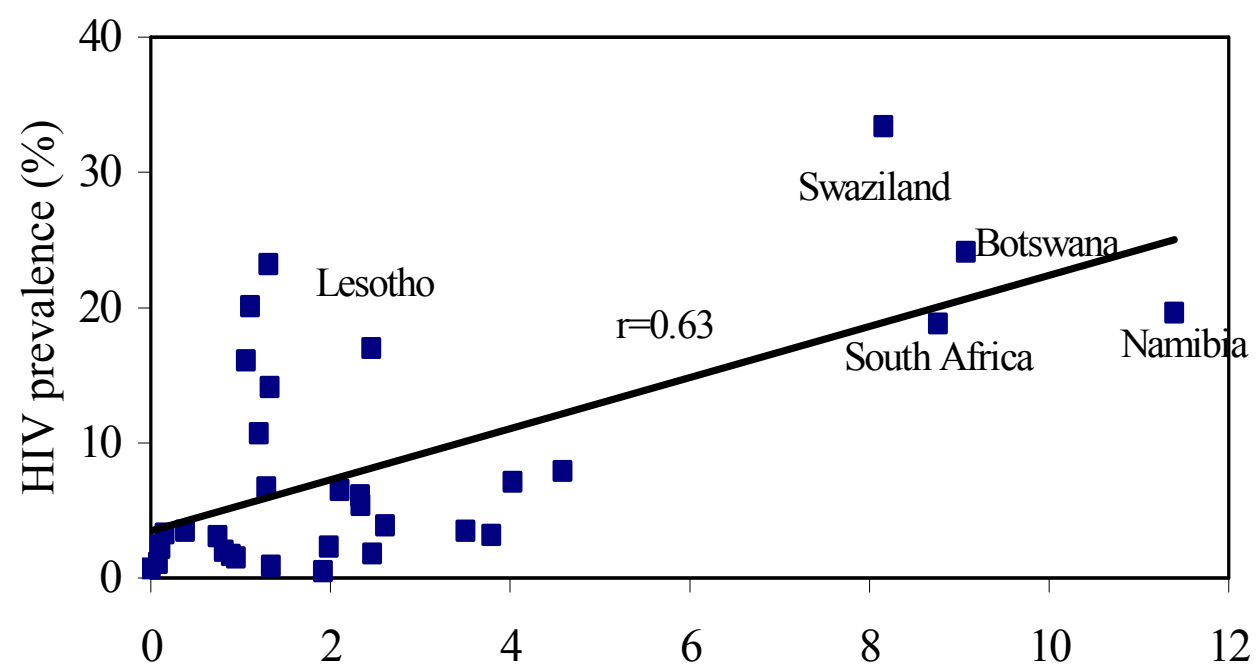

Difference between median ages at first marriage and at first sex 
Figure 5 Rural and urban median age at first sex and first marriage, average of 32 countries in sub-Saharan Africa

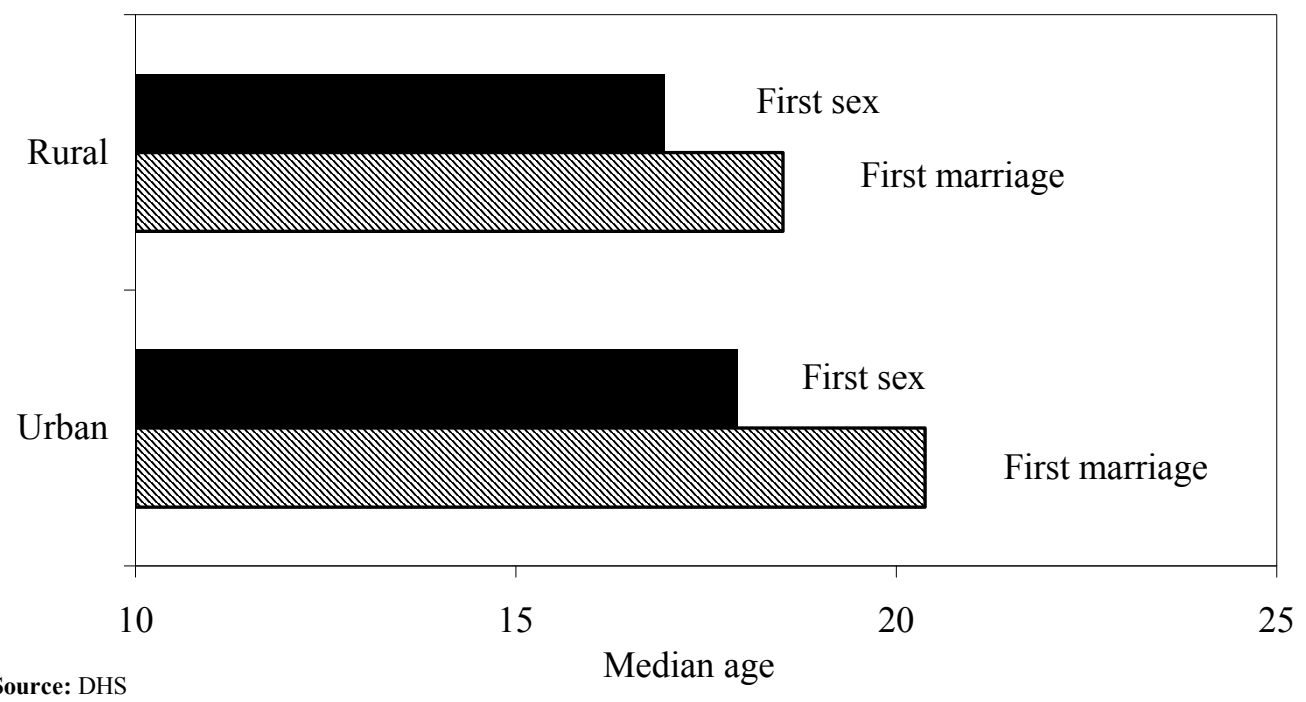

Figure 6 Odds ratios for HIV infection associated with a year of exposure before and after first marriage in Ghana, Kenya, and a Tanzanian ANC study, and HIV incidence in Rakai

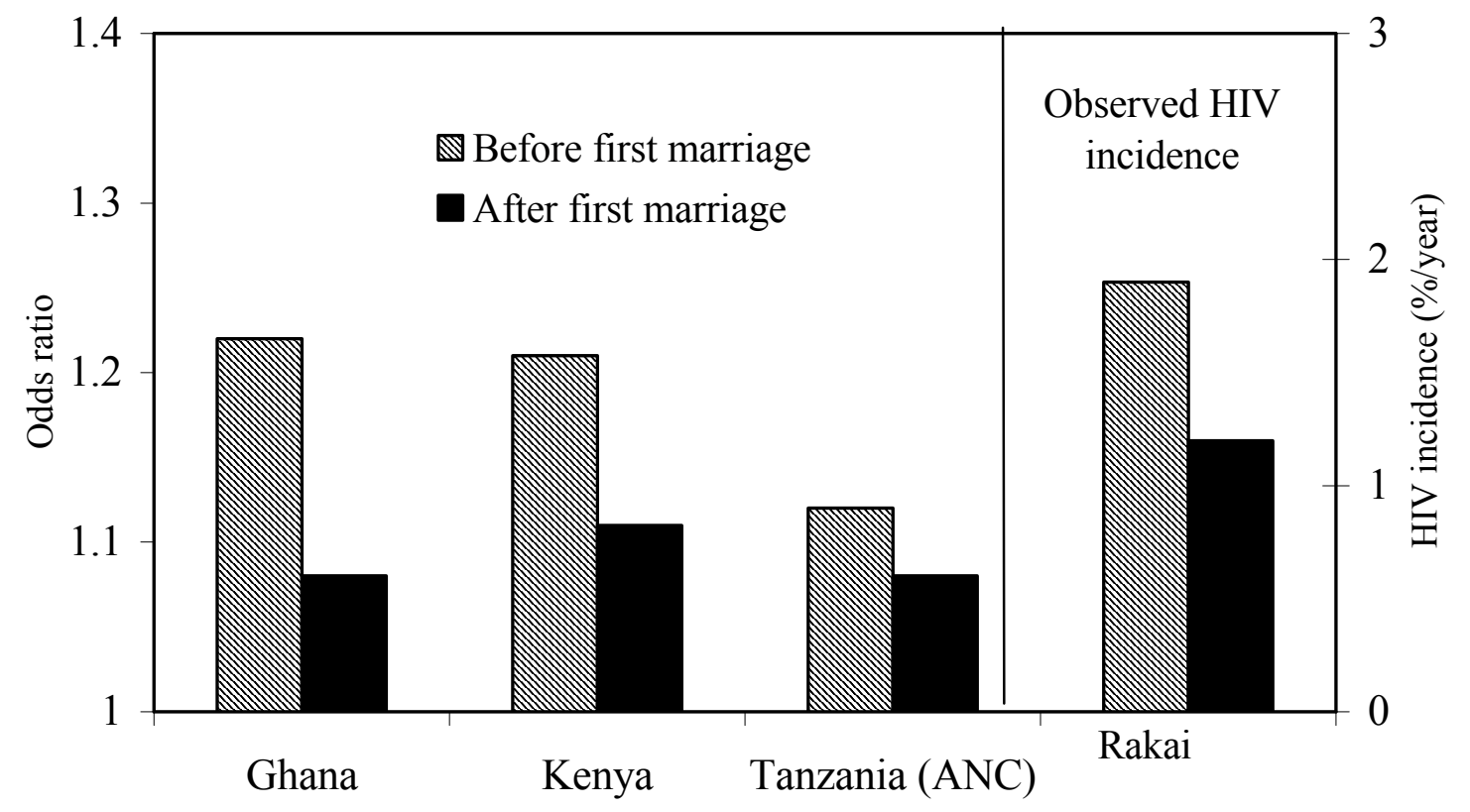

Source: Table 4; Zaba et al. 2005a; Gray et al. 2004 


\section{REFERENCES}

Anderson, R.M. 1996. The spread of HIV and sexual mixing patterns, in J. Mann and D. Tarantola (eds.), AIDS in the World II. New York: Oxford University Press, pp. 71-86.

Anderson, R.M. 1999. Transmission dynamics of sexually transmitted infections, in K.K. Holmes, P.F. Sparling, P-A Mardh, et al. (eds.), Sexually Transmitted Diseases, 3rd ed. New York: McGraw-Hill, pp. 25-37.

Auvert, B., A. Buvé, et al. 2001. Ecological and individual level analysis of risk factors for HIV infection in four urban populations in sub-Saharan Africa with different levels of HIV infection, AIDS 15 (Suppl 4): S15-S30.

Bailey, R.C., F.A. Plummer, and S. Moses. 2001. Male circumcision and HIV prevention: current knowledge and future research directions, Lancet Infectious Diseases, 1: $223-231$.

Buvé, A., M. Caraël, R.J. Hayes et al. 2001. The multicentre study on factors determining the differential spread of HIV in four African cities: Summary and conclusions, AIDS 15 (Suppl 4): S127-S131.

Bracher, M., G. Santow, and S.C. Watkins. 2003. “' 'Moving' and marrying: Modelling the HIV infection among newly-weds in Malawi," Demographic Research Special Collection (www.demographic-research.org)

Caldwell, J.C. 2000. Rethinking the African AIDS epidemic, Population and Development Review, 26: 117-135.

Cameron, D.W., J. N. Simonsen, L. J. D’Costa, et al. 1989. Female to male transmission of human immunodeficiency virus type 1: Risk factors for seroconversion in men, Lancet 2: 403-407.

Caraël, M., and K.K. Holmes. 2001. Dynamics of HIV epidemics in sub-Saharan Africa: Introduction, AIDS 15 (Suppl 4): S1-S4.

Caraë1, M., 1995. Sexual behavior, in J. Cleland and B. Ferry (eds.), Sexual Behavior and AIDS in the Developing world. London: World Health Organization, Taylor \& Francis, pp. 75-121.

Central Bureau of Statistics (CBS), Kenya, Ministry of Health (MOH), and ORC Macro. 2004. Kenya Demographic and Health Survey, 2003, Calverton, Maryland: CBS, $\mathrm{MOH}$ and ORC Macro.

Clark, S. 2004. Early marriage and HIV risks in sub-Saharan Africa, Studies in Family Planning, 35(3): 149-160. 
Cleland, J., J.T. Boerma, M. Caraël, and S.S. Weir. 2004a. Monitoring sexual behaviour in general populations: A synthesis of lessons from the past decade. Sexually Transmitted Infections, 80 (Suppl II): ii1-ii7.

Cleland, J., J.T. Boerma, M. Caraël, and S.S. Weir (eds.). 2004b. Measurement of sexual behavior, Sexually Transmitted Infections, 80 (Suppl II): ii1-ii 90.

Cleland, J., and B. Ferry (eds.). 1995. Sexual Behavior and AIDS in the Developing World. London: World Health Organization, Taylor \& Francis.

Ghana Statistical Service (GSS), Noguchi Memorial Institute for Medical Research (NMIMR), and ORC Macro. 2004. Ghana Demographic and Health Survey 2003. Calverton, Maryland: GSS, NMIMR and ORC Macro.

Gray, R., F. Nalugoda, D. Serwadda, and M.J. Wawer. 2004. Marriage and HIV risk: Data from Rakai, Uganda. Presentation made at workshop on marriage and HIV risk, Nov. 2004, New York: Population Council.

Halperin, D. and H. Epstein. 2004. Concurrent sexual partnerships help to explain Africa's high HIV prevalence: Implications for intervention, Lancet 364: 4-6.

Halperin, D. and R.C. Bailey. 1999. Male circumcision and HIV infection: Ten years and counting, Lancet 354: 1813-1815.

Kelly, R., R. Gray, N. Sewankambo, D. Serwadda, F. Wabwire-Mangen, T. Lutalo et al. 2003. Age differences in sexual partners and risk of HIV-1 infection in rural Uganda, Journal of Acquired Immune Deficiency Syndromes, 32(4): 446-451.

Koopman, J.S., J.A. Jacquez, G.W.Welch, et al. 1997. The role of early HIV infection in the spread of HIV through populations, Journal of Acquired Immune Deficiency Syndromes 14: 249-258.

Morris, M., and M. Kretzschmar. 1997. Concurrent partnerships and the spread of HIV. AIDS 11: 681-683.

Nnko S., J.T. Boerma, M. Urassa, G. Mwaluko, and B. Zaba. 2004. Secretive females or swaggering males? An assessment of the quality of sexual partnership reporting in rural Tanzania. Social Science \& Medicine 59:299-310.

Orubuloye, I.O., J. Caldwell, P. Caldwell, and G. Santow. 1994. Sexual networking and AIDS in sub-Saharan Africa, in I. O. Orubuloye, J. Caldwell, and G. Santow (eds.), Sexual Networking and AIDS In Sub-Saharan Africa: Behavioral Research and the Social Context. Health Transition Series No. 4, Canberra: Australian National University. 
Pilcher, C.D., H.C. Tien, J. J. Eron, et al. 2004. Brief but efficient: Acute HIV infection and the sexual transmission of HIV. Journal of Infectious Diseases 189: 17851792.

Quinn, T.C., M. Wawer, N. Sewankambo, D. Serwadda, C. Li, F. Wabwire-Mangen, et al. 2000. Viral load and heterosexual transmission of human immunodeficiency virus type 1, New England Journal of Medicine 342: 921-929.

Shapiro, R. 2002. Drawing lines in the sand: The boundaries of the HIV pandemic in perspective, Social Science and Medicine 55: 107-110.

Shiboski, S.C. and N.S. Padian. 1998. Epidemiological evidence for time variation in HIV infectivity, Journal of Acquired Immune Deficiency Syndromes and Human Retrovirology 19: 527-535.

Spark-du Preez, N., B. Zaba, C. Nyamukapa, M. Mlilo, and S. Gregson. 2004. "Kusvika taparadzaniswa nerufu" (Until death do us part), African Journal of AIDS Research 3(1): 81-91.

UNAIDS. 2006. Report on the global AIDS epidemic. Joint United Nations Programme on HIV/AIDS. New York: United Nations.

United Nations. 2000. "World Marriage Patterns 2000," Population Division of the Department of Economic and Social Affairs (DESA). New York: United Nations

Wawer, M.J., R.H. Gray, N.K. Sewankambo, D. Serwadda, et al. 2005. Rates of HIV-1 transmission per coital act by stage of HIV-1 infection, in Rakai, Uganda, The Journal of Infectious Diseases 191 (1 May): 1403-1409.

Wendell, B. and E. Werker. 2004, "Male circumcision and the impact of AIDS in Africa." (Unpublished manuscript, November 2004).

Weiss, H.A., M.A. Quigley, and R. J. Hayes. 2000. Male circumcision and risk of HIV infection in sub-Saharan Africa: A systematic review and meta-analysis. AIDS 14: 2361-2370.

Zaba, B., J.T. Boerma, and R. White. 2000. Monitoring the AIDS epidemic using HIV prevalence data among young women attending antenatal clinics: Prospects and problems, AIDS 14(11): 1633-1645.

Zaba, B., E. Pisani, E. Slaymaker and J.T. Boerma. 2004. Age at first sex: Understanding recent trends in African demographic surveys. Sexually Transmitted Infections, 80 (Suppl II): ii28-ii35. 
Zaba, B., E. Slaymaker, M. Marston, M. Urassa, et al. 2005a. Time at risk: Use of data on transitions between risk categories to explain individual HIV status and community HIV prevalence levels. Paper presented at IUSSP International Population Conference, Tours, July 18-23. (available at http://iussp2005. princeton.edu/download.aspx? submission $\mathrm{Id}=51733$ ).

Zaba, B., E. Slaymaker, M. Urassa, and J.T. Boerma. 2005b. The role of behavioral data in HIV surveillance. AIDS 19 Suppl 2:S39-S52 


\section{POLICY RESEARCH DIVISION WORKING PAPERS}

If still in print, single copies of up to three working papers from 1989 through 2003 are available free of charge.

Beginning with the 2004 issues, working papers are no longer available in print format. Instead they are distributed electronically. As each new paper is completed subscribers are notified by e-mail and a link to the paper is provided.

To subscribe to the Policy Research Division working paper e-mail notification list, or to obtain back issues from 1989 to 2003, please send your request to prdwp@popcouncil.org.

PDFs of recent issues are available at www.popcouncil.org/publications/wp/prd/rdwplist.html

2006

216 John Bongaarts, "Late marriage and the HIV epidemic in subSaharan Africa."

215 John Bongaarts, "How long will we live?"

214 Zachary Zimmer, Toshiko Kaneda, and Laura Spess, "Urban versus rural mortality among older adults in China."

213 Paul Demeny and Geoffrey McNicoll, "The political demography of the world system, 2000-2050."

212 Monica Grant and Kelly Hallman, "Pregnancy-related school dropout and prior school performance in South Africa."

211 Kelly Hallman, Sara Peracca, Jennifer Catino, and Marta Julia Ruiz, "Multiple disadvantages of Mayan females: The effect of gender, ethnicity, poverty, and residence on education in Guatemala."

210 Geoffrey McNicoll, "Policy lessons of the East Asian demographic transition."
209 Cynthia B. Lloyd, Cem Mete, and Monica J. Grant, "The implications of changing educational and family circumstances for children's grade progression in rural Pakistan: 1997-2004."

2005

208 James F. Phillips, Ayaga A. Bawah, and Fred N. Binka, "Accelerating reproductive and child health program development: The Navrongo Initiative in Ghana."

207 John Bongaarts and Griffith Feeney, "The quantum and tempo of life-cycle events."

206 Barbara S. Mensch, Monica J. Grant, and Ann K. Blanc, "The changing context of sexual initiation in sub-Saharan Africa."

205 Geoffrey McNicoll, "Population and sustainability."

204 John Bongaarts, "The causes of stalling fertility transitions." 
Binka, "How many years of life could be saved if malaria were eliminated from a hyperendemic area of northern Ghana?"

202 Barbara S. Mensch, Susheela Singh, and John B. Casterline, "Trends in the timing of first marriage among men and women in the developing world."

201 Zachary Zimmer, "Active life expectancy and functional limitations among older Cambodians: Results from a 2004 survey."

200 Brian Wells Pence, Philomena Nyarko, James F. Phillips, and Cornelius Debpuur, "The effect of community nurses and health volunteers on child mortality: The Navrongo Community Health and Family Planning Project."

199 Zachary Zimmer, Linda G. Martin, Mary Beth Ofstedal, and Yi-Li Chuang, "Education of adult children and mortality of their elderly parents in Taiwan."

198 Mian Bazle Hossain, James F. Phillips, and Thomas K. LeGrand, "The impact of childhood mortality on fertility in six rural thanas of Bangladesh."

197 Kristine R. Baker, Mary Beth Ofstedal, Zachary Zimmer, Zhe Tang, and Yi-Li Chuang, "Reciprocal effects of health and economic well-being among older adults in Taiwan and Beijing."

196 Mark R. Montgomery and Paul C. Hewett, 'Poverty and children's schooling in urban and rural Senegal."

195 Luciana Suran, Sajeda Amin, Lopita Huq, and Kobita Chowdury, "Does dowry improve life for brides? A test of the bequest theory of dowry in rural Bangadesh."

194 Barbara S. Mensch, Monica J. Grant, Mary P. Sebastian, Paul C. Hewett, and Dale Huntington. "The effect of a livelihoods intervention in an urban slum in India: Do vocational counseling and training alter the attitudes and behavior of adolescent girls?"

93 Amanda Ritchie, Cynthia B. Lloyd, and Monica Grant. "Gender differences in time use among adolescents in developing countries: Implications of rising school enrollment rates."

192 John Bongaarts. "Long-range trends in adult mortality: Models and projection methods."

191 John Koku Awoonor-Williams, Ellie S. Feinglass, Rachel Tobey, Maya N. Vaughan-Smith, Frank K. Nyonator, Tanya C. Jones, and James F. Phillips, "Bridging the gap between evidence-based innovation and national healthsector reform in Ghana."

190 Kelly Hallman, "Socioeconomic disadvantage and unsafe sexual behaviors among young women and men in South Africa."

189 Toshiko Kaneda, Zachary Zimmer, and Zhe Tang, "Differentials in life expectancy and active life expectancy by socioeconomic status among older adults in Beijing." 
188 Cynthia B. Lloyd and Monica J.

Grant, "Growing up in Pakistan:

The separate experiences of males and females."

187 Zachary Zimmer, Xianghua Fang, Toshiko Kaneda, Zhe Tang, and Julia Kwong. "Trends and transitions in children's coresidence with older adults in Beijing municipality."

186 Sajeda Amin and Alaka M. Basu. "Popular perceptions of emerging influences on mortality and longevity in Bangladesh and West Bengal."

185 John Bongaarts. "Population aging and the rising cost of public pensions."

184 Mark R. Montgomery and Paul C. Hewett. "Urban poverty and health in developing countries: Household and neighborhood effects." 